\title{
A second order model of noise in saturated semiconductor optical amplifiers
}

Öhman, Filip; Tromborg, Bjarne; Mørk, Jesper

Published in:

CLEO/Europe-EQEC 2005 Conference Digest CD

Link to article, DOI:

10.1109/EQEC.2005.1567183

Publication date:

2005

Document Version

Publisher's PDF, also known as Version of record

Link back to DTU Orbit

Citation (APA):

Öhman, F., Tromborg, B., \& Mørk, J. (2005). A second order model of noise in saturated semiconductor optical amplifiers. In CLEO/Europe-EQEC 2005 Conference Digest CD: Europhysics Conference Abstracts (Vol. vol. 29B). IEEE. https://doi.org/10.1109/EQEC.2005.1567183

\section{General rights}

Copyright and moral rights for the publications made accessible in the public portal are retained by the authors and/or other copyright owners and it is a condition of accessing publications that users recognise and abide by the legal requirements associated with these rights.

- Users may download and print one copy of any publication from the public portal for the purpose of private study or research.

- You may not further distribute the material or use it for any profit-making activity or commercial gain

- You may freely distribute the URL identifying the publication in the public portal

If you believe that this document breaches copyright please contact us providing details, and we will remove access to the work immediately and investigate your claim 


\section{A second order model of noise in saturated semiconductor optical amplifiers \\ Filip Öhman, Bjarne Tromborg and Jesper Mørk}

Research Center COM, DTU Build. 345v,DK-2800 Kgs. Lyngby, Denmark, fo@com.dtu.dk

\begin{abstract}
We have developed a second order model of spontaneous emission noise in semiconductor optical amplifiers (SOAs). The resulting noise distributions agree well with statistical simulations and explain the measured redistribution of noise in saturated SOAs.
\end{abstract}

\section{Introduction}

Semiconductor optical amplifiers (SOAs) have a number of promising applications within optical communication systems. In these applications the performance, as measured by the bit error rate (BER), depends on the noise distribution of the signal after the SOAs. It is therefore important to describe the noise in an SOA in detail. However, the saturation and nonlinear properties of the SOA make this description complicated. We have previously measured and simulated the probability density functions (PDFs) after amplification in a saturated SOA [1]. In this work we have developed a detailed model for describing the PDF of the noisy signal at the output of an SOA.

\section{The model}

The device model is based on the standard field equation and carrier rate equation. The spontaneous emission noise is included as a Langevin force in the field equation. The noise is considered as small perturbations and the field and gain are expanded in Volterra series to second order in the noise terms. This is an extension to the work of Shtaif et al. [2], which only included first order terms. The PDF is determined by finding the moment generating function (MGF) of the output power and calculating the Fourier transform of the characteristic function. From the MGF the central moments, and hence the standard deviation and skewness, can also be calculated.

\section{Results}

The results obtained in this work are compared to the measurements and statistical simulations presented in [1]. The top panel of Fig. 1 shows the measured PDFs together with non-central (n.c.) $\chi^{2}$-distributions with the same mean and standard deviation. The bottom panel shows the PDFs calculated using the second order model and the simulations as well as n.c. $\chi^{2}$ distributions calculated from the first order noise terms. The most obvious improvement of using the new model compared to the simulations is that it is possible to calculate the PDFs far out in the tails of the distributions, with a reasonable computation time.

The different models and the measurements can be quantitatively compared through the skewness of the distributions, which is defined as the normalised third order central moment. This is shown in figure 2, where the solid circles and triangles show the measurements and corresponding n.c. $\chi^{2}$-distributions, respectively. The open squares represent the simulations and the solid and dash-dotted lines represent the second order model and first order n.c. $\chi^{2}$-distribution, respectively.

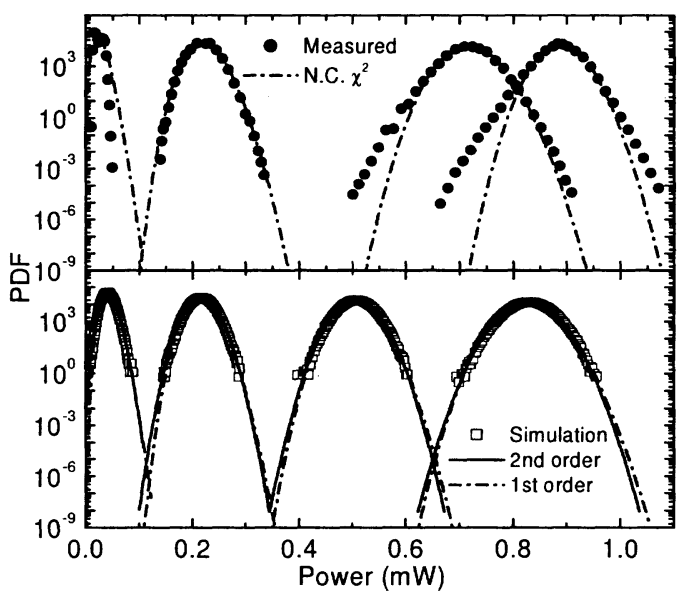

Fig. 1. Measured (top) and calculated (bottom) PDFs of the signal after an SOA.

Figure 2 shows that the non-linear noise redistribution in the SOA skews the distribution in the negative direction compared to the n.c. $\chi^{2}$-distribution. This effect is seen in the measurement and is considered in the simulations and second order model, but not in the first order case. Furthermore, excellent agreement is seen between the simulation and the second order model.

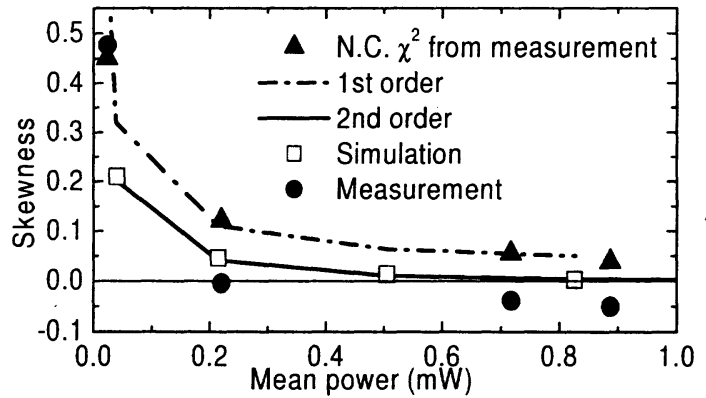

Fig. 2. Measured (solid circle) and calculated (open square and solid line) skewness of the PDFs.

\section{Conclusions}

The second order noise model is capable of describing the measured non-linear noise redistribution of an SOA. It agrees quantitatively with statistical simulations, but requires less computational power and allows results to be obtained far out in the tails of the PDFs, thus enabling accurate BER calculations.

\section{References}

[1] F. Öhman et al. Photonics Technol. Lett., vol. 17, pp. 16-18 (2005).

[2] M. Shtaif et al. J. Quantum Electron., vol. 34, pp.869-878 (1998). 